\title{
Cartografia dos Locais Turísticos de Poços de Caldas - MG, Brasil: um projeto
}

\author{
Cartography of Tourist Sites in Poços de Caldas - MG, \\ Brazil: a project
}

\section{José Adilson Dias Cavalcanti}

RESUMO: A cartografia dos locais turísticos é um poderoso instrumento de trabalho para o turismólogo, emora ainda pouco utilizado. Algumas experiências de aplicações da cartografia turística foram realizadas na cidade de Poços de Caldas-MG e tiveram como resultados o mapeamento do Parque Municipal Antônio Molinari, a confecção de guias da infra-estrutura turística e painéis de sinalização, além de um guia das águas minerais localizadas no centro da cidade. Esses levantamentos foram realizados pelos alunos do terceiro período do curso de Turismo da PUC-MG sob coordenação do professor responsável pela disciplina Cartografia no Turismo. Um dos resultados é apresentado neste artigo: o mapeamento do Parque Municipal Antônio Molinari.

PALAVRAS-CHAVE: cartografia; mapa; turismo; Poços de Caldas; parque municipal.

ABSTRACT: Some experiences of the tourist cartography of Poços de Caldas are introduced. In special, is show the mapping of the Parque Municipal Antônio Molinari, make to students of $3^{\circ}$ period of Tourism Course, under coordination of the professor of tourist cartography.

KEYWORDS: cartography; map; tourism; Poços de Caldas, park.

1. Doutor em Ciências pela uniCamp. Professor da disciplina Cartografia no Turismo na Puc-MG, Poços de Caldas. Contato: Rua Dr. Quirino, 1730/111-MF - 13015-913 - Campinas-sp; e-mail: adilson@pucpcaldas.br. 


\section{Introdução}

A Estância Hidromineral de Poços de Caldas está situada a sudoeste do Estado de Minas Gerais, próxima à divisa com o Estado de São Paulo, na Serra da Mantiqueira. A cidade ficou conhecida pelas suas águas sulfurosas termais de utilização terapêutica. As fontes de águas sulfurosas existentes na cidade são de natureza alcalina, sulfídrica, hipertermal e radioativa.

A cidade de Poços de Caldas apresenta um enorme potencial turístico, entretanto, alguns de seus atrativos têm sofrido depreciação com o passar do tempo, por conta do planejamento e gerenciamento inadequados, como é o caso do Parque do Véu das Noivas. O curso de turismo da PUC-MG, localizado nessa cidade, tem realizado diversas atividades, particularmente na disciplina Cartografia no Turismo, visando suprir parte do desenvolvimento e/ou mapeamento turístico de Poços de Caldas. Dentre as atividades destacam-se o mapeamento turístico do Parque Municipal Antônio Molinari, a confecção de painéis de sinalização turística e de roteiros temáticos da infra-estrutura da cidade que serve ao turista, bem como um guia das águas minerais localizadas no centro da referida cidade. Em relação aos roteiros temáticos da infra-estrutura, confeccionaram-se guias diferenciados de restaurantes, hotéis, bares noturnos, lojas de artesanato, livrarias e cafés. Tais levantamentos têm sido realizados pelos alunos do terceiro período do curso, orientados pelo professor responsável pela disciplina supra citada. Os trabalhos ainda são preliminares, mas devem culminar na produção de um sistema de informaçōes turísticas, utilizando cỏmo referência um sistema de informaçōes geográficas (GIS - Geographic Information System).

Os levantamentos realizados ao longo desses dois anos mostraram que Poços de Caldas, além dos atrativos turísticos, possui uma ótima infra-estrutura para o turista. Mas esse conjunto precisa ser reavaliado, estudado e trabalhado para que possa ser mais bem aproveitado pelos turistas que visitam a cidade. Durante os levantamentos, os alunos muitas vezes se mostraram decepcionados com a conservação de alguns dos atrativos, que estão em estado de total abandono, como é o caso da Estação Ferroviária Mongiana, do Parque Véu das Noivas e da Represa Saturnino de Brito.

A proposta de criação de um sistema de informação turística digital em rede, que integre atrativos, infra-estrutura e serviços, mostra-se bastante interessante. A funcionalidade desse tipo de sistema pode ser demonstrada quando um turista acessá-lo em um terminal de computador. Esse sistema, além de permitir que se visualize a maioria dos atrativos da cidade, elabora um roteiro, que pode ser impresso na forma de guia, incluindo o mapa dos locais turísticos, a infraestrutura e os serviços locais.

\section{O mapa turístico}

A cartografia pode ser entendida como a ciência da representação e do estudo da distribuição espacial dos fenômenos naturais e sociais em suas relaçōes e transformaçōes ao longo do tempo, buscando representar os aspectos da realidade de forma gráfica (Salichtchev, 1973; Martinelli, 2003). O mapa turístico poder ser considerado "Temático", por tratar um tema específico, mas ao mesmo tempo é considerado uma "Carta Especial", pois trata de um conhecimento de uma área específica (IBGE, 1999). As cartas temáticas surgiram em detrimento da sobreposição de diversos temas em um mesmo mapa, mas todo mapa, qualquer que seja ele, ilustra um tema (Joly, 2001).

Quando elaboramos mapas turísticos é comum haver sobreposição de temas, daí surgiu à idéia de produzir mapas "turísticos temáticos". Ao realizarmos um levantamento turístico na Estância Hidromineral de Poços de Caldas utilizando como tema central a água, surgiram os seguintes subtemas:

i) fontes de água sulfurosa quente (hipertermal) e fria (hipotermal);

ii) fontes de água potável;

iii) fontes ornamentais;

iv) balneários;

v) rios, represas e cachoeiras.

Daí conclui-se que um "Mapa Turístico" pode ser considerado uma "Carta Especial", que aborda os diversos temas do universo do Turismo.

Nos mapas turísticos são utilizadas as mais diversas linguagens para transmitir o conhecimento do espaço físico e cultural de um determinado local, desde mapas artísticos, realizados em perspectiva, até representaçōes técnicas, como imagens de satélites, fotografias aéreas, mapas topográficos e rodoviários. Além do mapa turístico, muitas vezes o turista utiliza-se dos mapas rodoviários para acessar as cidades ou para se deslocar em uma determinada região.

Entende-se o mapeamento turístico como o levantamento e a representação em mapa dos atrativos, dos serviços e da infra-estrutura que serve ao turista. Os produtos cartográficos são ferramentas básicas para o turismólogo. O mapa turístico pode ser utilizado para os mais diversos fins, desde a simples localização de atrativos turísticos de uma pequena cidade até o planejamento e o manejo turístico de uma região. O turismólogo utiliza-se muito pouco desses importantes produtos para trabalhar o conhecimento e o reconhecimento do espaço físico e cultural de uma determinada região. Atualmente, grande parte dos mapas turísticos é elaborada sem escala e com símbolos (ícones) inadequados, dificultando a 
leitura e a visualização dos atrativos. Uma das alternativas apontadas para a melhoria desses mapas é a busca pela padronização das representações dos atrativos turísticos, dos serviços e da infra-estrutura.

A classificação dos elementos turísticos e a padronização dos símbolos utilizados em placas de sinalização turística elaboradas pela Secretaria de Esportes e Turismo do Estado de São Paulo (1998) e pela EMBratur (2001) - por meio dos seus manuais de sinalização turística - representam um grande avanço na tentativa de padronizar as representações cartográficas nos mapas turísticos.

A padronização realizada pela Secretaria de Esportes e Turismo do Estado de São Paulo (1998), por meio do seu Manual de Sinalização Turística, propõe as seguintes categorias: i) atrativos turísticos; ii) equipamentos turísticos; e iii) infraestrutura de apoio turístico.

Os atrativos turísticos são classificados em naturais, histórico-culturais, manifestações e usos tradicionais populares, realizações técnicas e científicas contemporâneas.

Os equipamentos turísticos estão agrupados em meios de hospedagem, alimentação e abastecimento, áreas de recreação, áreas de práticas esportivas e diversões.

Já a infra-estrutura comporta os sistemas de transporte terrestre, marítimo e aéreo, bem como os sistemas de comunicação, segurança e saúde.

Essa sistematização, apesar de ser um grande avanço na padronização das representações turísticas em placas de sinalização, mostra-se, em alguns casos, generalista quando adaptada para utilização em mapas turísticos temáticos. Citamos como exemplo duas importantes cidades turísticas mineiras: Poços de Caldas e Ouro Preto.

Na estância hidromineral de Poços de Caldas, o tema principal é a água e, dessa forma, temos que diferenciá-lo em fontes de águas minerais sulfurosas quentes (hipertermais), sulfurosas frias (hipotermais) e potáveis. Já na histórica cidade de Ouro Preto, o museu é um dos temas principais, e terá de ser distinguido entre museu de arte sacra, histórico e científico (como o conjunto de museus de ciência e tecnologia da Escola de Minas).

A partir desses dois exemplos, pode-se observar que as representações cartográficas precisam ser mais detalhadas. Assim, a busca pela padronização das representações dos aspectos turísticos em mapa mostra-se bastante interessante, mas pouco eficiente, quando se trata de mapas mais detalhados, ou seja, temáticos.

O mapa turístico possui a função de conhecimento do acervo de atrações turísticas de um local e também serve de guia para o turista se localizar, podendo planejar um passeio mediante o conhecimento das distâncias a serem percorri- das. Atualmente, existe uma grande quantidade de mapas turísticos disponibilizados na forma de guias, como, por exemplo, os guias visuais da Folha de São Paulo e os guias turísticos Quatro Rodas; também são encontrados em revistas como Viagem \& Turismo, Próxima Viagem, Trilhas e Turismo Rural, dentre outras.

Nos locais turísticos, quase sempre existem mapas sendo comercializados. Estes, por sua vez, utilizam uma gama de símbolos e números difíceis de serem memorizados ou identificados. Daí a necessidade de se propor uma padronização das representações.

Ao estudar determinados elementos da cidade de Poços de Caldas, percebemos a complexidade que pode atingir as representações em um mapa turístico. Os painéis de sinalização são utilizados na representação dos principais atrativos turísticos da cidade, como as termas, os museus, as praças e jardins, as fontes, as cachoeiras, os parques e os prédios históricos, entre outros. Nos guias de serviços temos os hotéis, os restaurantes, os bares, as livrarias, os cafés, as lojas de artesanato e arte, os cinemas etc. Já no guia das águas minerais localizadas no centro, temos as fontes de águas sulfurosas (quentes e frias), as fontes de água potável e os balneários. Este artigo, por sua vez, apresenta somente o mapeamento turístico do Parque Municipal Antônio Molinari.

Nesse parque existem pelo menos três modalidades de representações: áreas de práticas esportivas, recreação e infra-estrutura. As áreas de práticas esportivas são as quadras de voleibol, basquetebol, futebol de salão, voleibol de areia, campo de futebol society, a área de ginástica e as pistas de cooper e de bicicross. As áreas de recreações são representadas pelos parques infantis e pelos bosques. A infra-estrutura é representada pelos quiosques, banheiros, fontes e postos de segurança.

\section{Mapeamento do Parque Municipal Antônio Molinari}

O mapeamento do Parque Municipal Antônio Molinari foi realizado pelos alunos da disciplina Cartografia no Turismo do terceiro período do curso de Turismo, e teve como objetivo principal treiná-los na prática de mapeamento planimétrico de pequenas áreas mediante o método de caminhamento topográfico, utilizando bússola e trena. Como resultado, obtivemos o mapa turístico do parque. A metodologia utilizada foi adaptada a partir da técnica de mapeamento espeleológico (Cavalcanti, 1996), desenvolvida na Sociedade Excursionista e Espeleológica da Escola de Minas de Ouro Preto, e também mediante as experiências do professor da disciplina em mapeamentos topográficos, geológicos, espeleológicos e de trilhas. 


\section{Metodologia}

\section{Levantamento de campo}

No levantamento topográfico foram utilizados os métodos de poligonal aberta, fechada e irradiação. Geralmente, esses métodos são aplicados em conjunto. As equipes de trabalho foram assim constituídas: um operador de bússola, dois operadores de trena, um anotador de planilha, um croquista e um auxiliar (Figura 1). Antes de iniciar o mapeamento foi realizado um reconhecimento da área do parque para se ter idéia dos elementos que seriam representados e para a escolha da escala de trabalho.

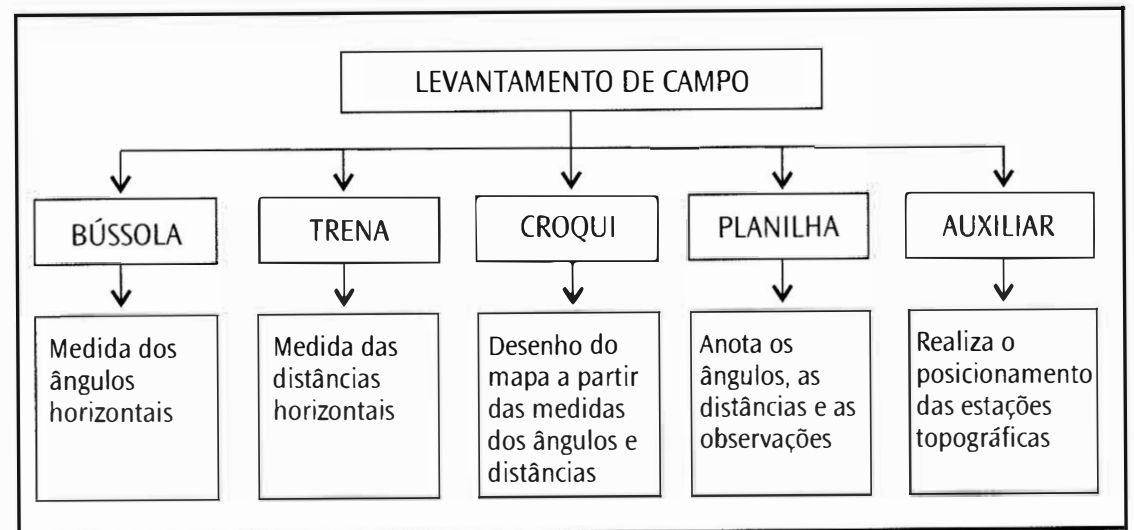

Figura 1. Fluxograma das atividades de campo

Um aluno na posição de "operador de bússola", munido de uma "bússola Brunton", realizou as leituras dos azimutes (ângulo que o alinhamento faz com o norte). As leituras foram feitas com vistas de ré e de vante, de forma a tornar o mapeamento mais dinâmico e preciso. Ao mesmo tempo que se realizavam as leituras, o operador de bússola teve de designar as novas estações topográficas com ajuda de um auxiliar, que fez as marcações dessas estações utilizando cartões com o nome delas. A dupla de operadores de trena (ponta-de-trena e pé-de-trena) alinhou a trena entre as estações, e o ponta-de-trena fez a leitura da distância horizontal de ré e de vante. $\mathrm{O}$ anotador, de posse da planilha topográfica, anotou todas as medidas de ângulos e distâncias, além das observações relacionadas a cada posição. $O$ croquista - com auxílio das medidas dos ângulos e das distâncias anotadas na planilha e das observações de campo - realizou o desenho na escala predeterminada, utilizando uma folha de papel milimetrado, um escalímetro e um transferidor (Cavalcanti, 1996).

\section{Trabalho de gabinete}

De posse dos dados, os grupos de alunos passaram para a fase de confecção do mapa. O primeiro procedimento foi passar para o papel milimetrado os dados topográficos, isto é, o caminhamento topográfico. Em seguida, foi sobreposto o croqui de campo ao caminhamento topográfico e, posteriormente, foram colocados símbolos para representar os diversos aspectos mapeados no parque. Ao mapa foram acrescentados o norte, a escala gráfica, a escala numérica, o quadro de convenções e o título do mapa. Os principais símbolos utilizados para representar os aspectos mapeados no parque podem ser vistos no quadro de convenções (Figura 2).

A concepção final do mapa foi realizada em papel vegetal e no formato digital. O mapa ora apresentado foi confeccionado com base nos dados de campo levantados pelos alunos e também por meio da planta topográfica do MAE, na escala 1:2.000. Dessa forma, o mapa final foi composto mediante o mapeamento detalhado do Parque Municipal Antônio Molinari, e também pelas vias de acesso ao parque. O mapa também foi confeccionado em meio digital, utilizando-se os softwares Autocad e Corel Draw (Figura 3).

\section{Análise do mapa}

O Parque Municipal Antônio Molinari, além de atrativo turístico, é também uma área de esporte e de lazer na cidade de Poços de Caldas. Além da infra-estrutura voltada para o esporte, o parque possui áreas de recreação infantil, de descanso e um palco para shows. No mapeamento distinguimos três seguimentos distintos: esporte, laser e infra-estrutura. Esses seguimentos foram representados por vinte ícones diferentes, dentre os quais muitos ainda não são padronizados.

Para a prática esportiva, o parque conta com dois campos de futebol society (com grama), duas quadras de futebol de salão, duas quadras de basquete, duas quadras de voleibol (piso de concreto), uma quadra de voleibol de areia, duas áreas de ginástica, uma pista de cooper e uma pista de bicicross. Em relação ao laser, o parque possui duas áreas de recreação infantil, dois bosques e áreas de descanso. Já em relação à infra-estrutura, possui duas guaritas de segurança, dois 


Práticas Esportivas
Area de Ginástica

Figura 2. Quadro de convenções mostrando os símbolos utilizados para representar os aspectos do Parque Municipal Antônio Molinari

banheiros, uma fonte de água potável, diversos quiosques e um estacionamento. No mapa do parque vislumbram-se ainda outros aspectos da área, como o gramado, as árvores, o riacho, um lago e as ruas de acesso.

Os símbolos utilizados no mapa, em sua maioria, foram obtidos no Guia Brasileiro de Sinalização Turística (EMBRATUR, 2001). Os símbolos utilizados para representar os esportes praticados nas quadras (futebol, basquetebol, voleibol) foram desenvolvidos pelo professor da disciplina, em alusão às bolas utilizadas para as práticas esportivas citadas. Todos os ícones são representados em preto-ebranco. Os gramados, as árvores, as praças e os canteiros centrais da avenida são representados em tons de verde; o rio e o lago em tons de azul. Tais cores são padrão em mapas topográficos.

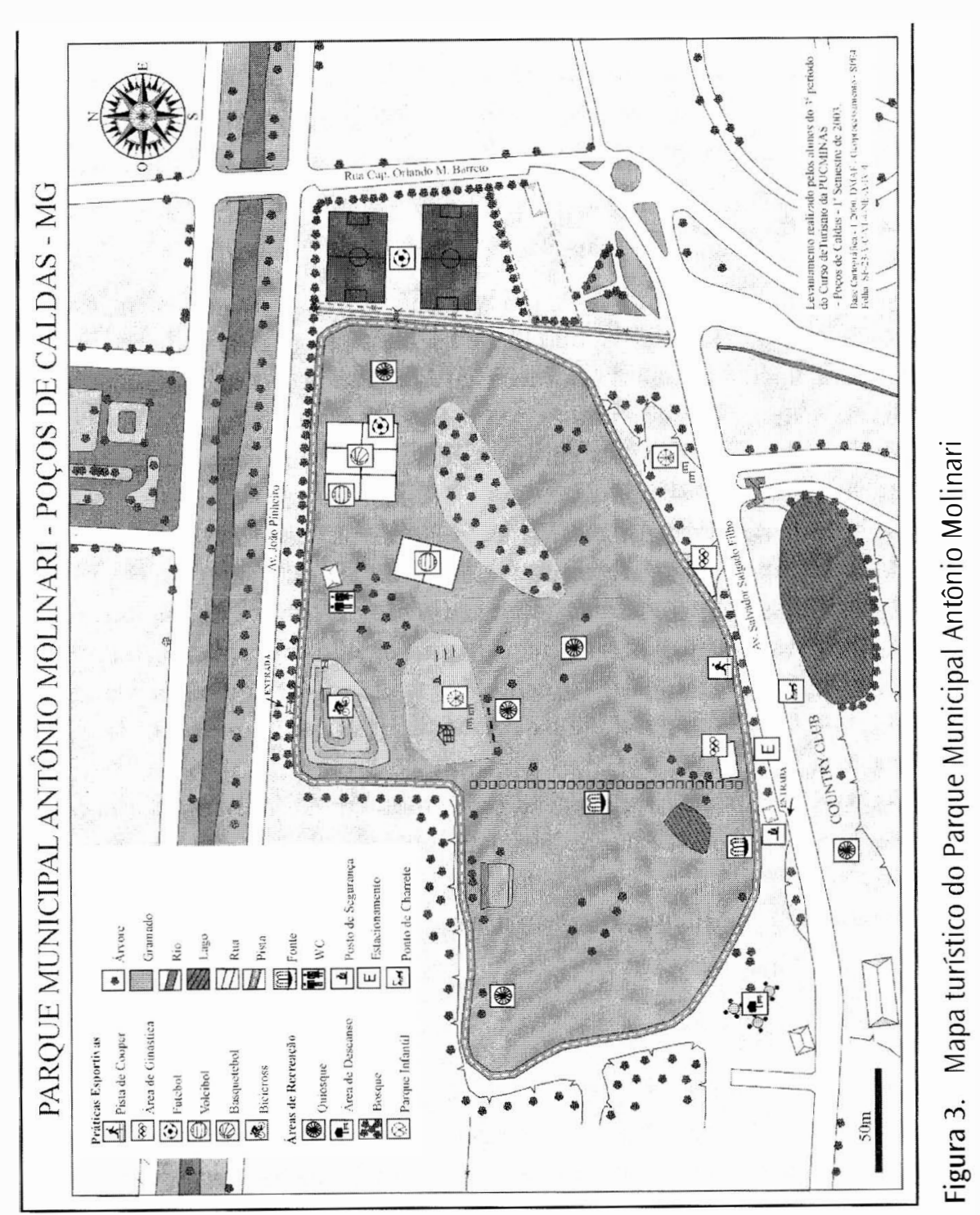


Apesar de a área do parque ser relativamente pequena, pode-se notar a complexidade que um mapa turístico pode apresentar. No entanto, os mapas turísticos ainda têm sido, em muitos casos, tratados como meras ilustrações de folders e revistas. O mapeamento dos aspectos turísticos (de um parque, de uma cidade, de uma região, de um Estado, etc.) traz não só o conhecimento do acervo, mas dota o turismólogo de uma visão privilegiada para o planejamento, monitoramento e para a implantação de projetos (hotéis, resorts, centros de convenções etc.).

\section{Considerações finais}

Atualmente, a produção de mapas tem sido facilitada pelo desenvolvimento da tecnologia digital e pela disponibilidade de bases cartográficas digitais, como as imagens de satélite de alta resolução, as ortofotos e as cartas topográficas nas mais diversas escalas. Nesse sentido, a cidade de Poços de Caldas também é privilegiada, pois conta com uma base cartográfica do município na escala 1:10.000, e uma da área urbana na escala 1:2.000.

A partir do mapeamento detalhado dos atrativos turísticos, da infra-estrutura e dos serviços da cidade de Poços de Caldas, pode-se chegar a uma padronização das representações, seja dos atrativos turísticos, da infra-estrutura, seja dos serviços oferecidos aos turistas que freqüentam a cidade. A apresentação de uma proposta de padronização das representações em mapa nos eventos da área de turismo faz-se necessária para que haja uma discussão mais aprofundada sobre essa questão.

O mapa do Parque Municipal Antônio Molinari foi utilizado como referência para mostrar uma técnica de levantamento topográfico prático e acessível. Constatou-se também que as representações icônicas nos mapas turísticos podem ser complexas, portanto, merecem um estudo mais aprofundado.

\section{Agradecimentos}

Agradeço aos alunos da disciplina Cartografia no Turismo, do terceiro período do curso de Turismo (anos 2001 e 2002), que participaram da confeç̧ão dos guias de equipamentos turísticos; aos alunos do primeiro semestre de 2003, pela ativa participação no levantamento de dados e na confecção do Mapa Turístico do Parque Municipal Antônio Molinari; aos alunos do segundo semestre de 2003, pela produção dos painéis de sinalização de diversos setores da cidade; e aos alunos do primeiro semestre de 2004, que participaram da confecção do guia das águas minerais do centro de Poços de Caldas.

\section{Referências bibliográficas}

CAVALCANTI, J. A. D. 1996. Mapeamento espeleológico. Ouro Preto, MG: Sociedade Excursionista e Espeleológica - SEE.

DMAE. Carta topográfica, escala 1:2.000. Poços de Caldas - MG.

EMBRATUR; IPHAN; DENATRAN. 2001. Guia brasileiro de sinalização turística.

FOLHA DE S. PAULO, 1997. Guia visual.

GUIA QUATRO RODAS. 2000. Atlas e mapas rodoviários. São Paulo.

IBGE. 1999. Noçōes básicas de cartografia. Manuais Técnicos em Geociências. Rio de Janeiro.

JOLY, F. 2001. A cartografia. Trad. Tânia Pellegrini. Campinas, SP: Papirus.

MARTINELLI, M. 2003. Mapas da geografia e cartografia temática. São Paulo: Contexto.

SALICHTCHEV, K. A. 1973. Some refletions on the subject and method of cartography after the Sixth International Cartographic Conference. The Canadian Cartographer, 10 (2): 106-111.

SECRETARIA DE ESPORTES E TURISMO DO ESTADO DE SÃO PAULO. 1998. Manual de sinalização turística. São Paulo: Coordenadoria de Turismo.

Recebido em 30/03/2004 ( $1^{\text {a }}$ versão) e 19/09/2004 (2a versão).

Aprovado em 18/10/2004. 